\title{
Cabin Thermal Needs: Modeling and Assumption Analysis
}

\author{
Florent Brèque Maroun Nemer \\ MINES ParisTech, PSL Research University, Center for energy Efficiency of Systems \\ 5 rue Léon Blum, Palaiseau, 91120, France \\ florent.breque@mines-paristech.fr
}

\begin{abstract}
Interest for cabin thermal needs has strongly increased for the past 10 years, particularly due to heating. Indeed, the development of electric and hybrid vehicles stressed the need to rethink the cabin thermal design and the HVAC, this high-consuming auxiliary, which can dramatically decrease the vehicle electric range. Thus, this paper presents a detailed transient and mono-zonal model of a car cabin in order to predict the thermal needs. The model is developed using the MODELICA language via the DYMOLA environment. It considers conduction, convection, radiation heat transfers as well as the HVAC and water vapor impacts. The different assumptions of the model are discussed and important considerations usually not discussed are highlighted. The thermal loads are also analyzed. Finally, the heating and cooling thermal needs are computed for steady state mode and for convergence mode as well as for varying recirculation ratios. This work is useful to better understand the whys and wherefores related to the cabin thermal needs.
\end{abstract}

Keywords: $\quad$ thermal model, vehicle cabin, cabin thermal needs, HVAC, heating, Air-conditioning, electric vehicle.

\section{Introduction}

For the past ten years, the electric vehicle developments and deployments have strongly accelerated. However, one of the major concerns with those vehicles is their low range. Hence, a lot of effort has been made to improve the vehicle range. It appeared that a major load for the battery is actually the HVAC system, which can consume as much energy as the motor in some conditions. Thus, additional development is necessary to decrease the HVAC energy consumption. One solution is to use a heat pump instead of the electric heaters typically used.

The work presented in this paper is part of a project which aims at developing a heat pump technology for electric vehicles. The project focuses particularly on the frosting issue with regards to the evaporator. Another important aspect of the project is to evaluate the gains that can be obtained from using heat pumps and evaluate other thermal strategies. In order to do so, a detailed thermal model of the cabin is required. Different models have already been presented in the literature. They are of different types.

A first category is composed of the CFD models (Versteeg and Malalasekera, 2007). Some authors use those models to evaluate the thermal comfort (Fujita et al., 2001; Kataoka and Nakamura, 2001; Sevilgen and Kilic, 2012). Others study the impact of specific aspects such as the windows opening, the glazing properties or the air quality (Al-Kayiem et al., 2010; Fujita et al., 2001; Zhu et al., 2010).

On the other hand, lumped models, also called mono-zonal model, have been developed. Here, the cabin air is modeled by a single node and is therefore considered homogeneous (Marcos et al., 2014; Wischhusen, 2012). Those types of models are mainly used to study the impact of some factors on the thermal load ( $\mathrm{Li}$ and Sun, 2013; Torregrosa-Jaime et al., 2015) but can also be used for studying HVAC control (Sanaye et al., 2012).

Finally, an intermediary approach between the two previous exists and is called the zonal approach. It consists in defining several air lumped nodes in a single air volume and linking them in order to exchange mass (Boukhris et al., 2009). The challenge here is then to use or develop a proper flow model between the nodes (Daoud and Galanis, 2008; Inard et al., 1996). It can be seen as a simplified CFD approach in some cases. For vehicle applications, this approach is sometimes used but usually only with two nodes in the cabin (Torregrosa-Jaime et al., 2015; Wischhusen, 2012).

Based on this review, it clearly appears that the most relevant category of models to study the cabin thermal needs takes the mono-zonal approach. It is therefore the one that will be developed in this paper.

Regarding the thermal need analysis, several authors have studied it (Iskandar, 2010; Li and Sun, 2013; Marcos et al., 2014; Mezrhab and Bouzidi, 2006; Torregrosa-Jaime et al., 2015). However, they focused on air-conditioning needs (since it was the important aspect for conventional cars) but neglect heating needs. Furthermore, they have studied a limited number of cases and the assumptions have not been discussed. 
Consequently, the aim of this paper is to address those issues.

To do so, a model is developed using the MODELICA language via the DYMOLA environment. First, an overview of the top level model is presented in this paper. Then the main models are presented. Through the model descriptions, the different assumptions of the model are discussed and important considerations usually not discussed are pointed out. Then, in the result section, the steady state mode is first analyzed, followed by the convergence mode, which correspond to the initial transient warm-up or cooldown phase. The thermal loads are analyzed for the steady state case and, for both mode, a sensitivity analysis is performed. Finally, cooling and heating thermal needs are computed.

\section{Mathematical model}

\subsection{Model overview}

Figure 1 is a view of the cabin top level model in the DYMOLA environment. It is composed of several models. First, the cabin model itself includes the thermal network and the cabin air node (moist air). The HVAC model handles the recirculation air flow and the heating/cooling of the air. It is operated by a controller which either adjusts the thermal power to reach the targeted cabin air temperature or imposes a constant thermal power depending on the user choise. The atmosphere model imposes the weather conditions. Finally 5 records are used here as an interface for model parameterization.

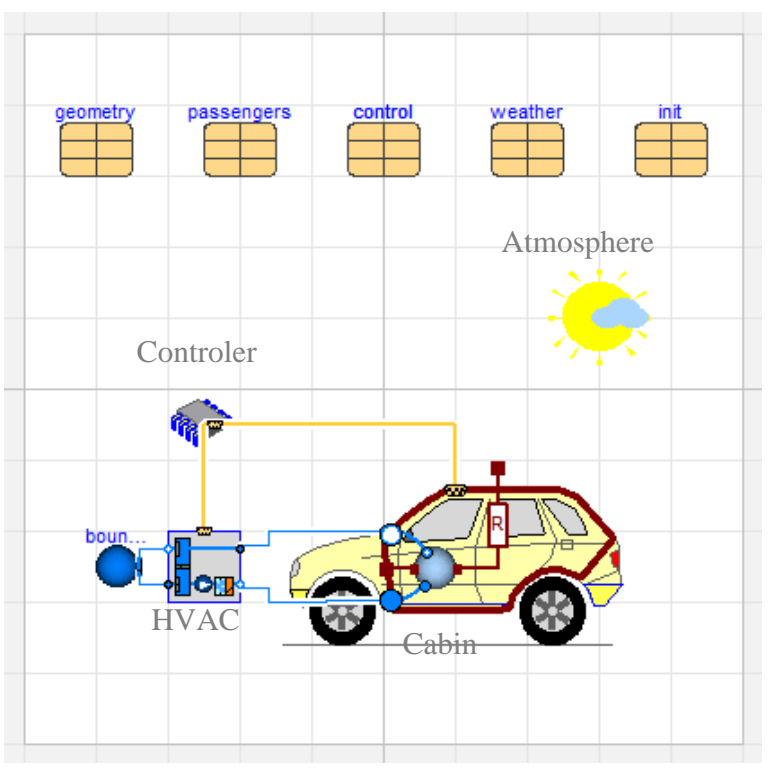

Figure 1. Cabin top level model in DYMOLA.

Figure 3 is a schematic of the complete model. It can be observed that the model is divided in two parts.

First, there is the thermal network. It includes the heat transfer exchanges with the exterior. In addition, two cabin internal nodes are defined and connected between each other and to the walls. The first corresponds to the cabin air and the second to the internal solid mass (seats, dash board...).

Second, a fluid flow network is represented. It represents the moist air flows. It is particularly of interest since it computes the properties of the recirculation air, it determines the water vapor condensation rate in the evaporator and also computes the water vapor mass balance in the cabin taking into account passenger water vapor generation.

This model is described in more details in the following sections.

\subsection{Atmosphere model}

Basically, the atmosphere model is quite simple. It is here to provide 5 inputs: outside air temperature, outside air humidity, solar direct and diffuse flux as well as the sun direction vector. One can directly provides this information as parameters. Instead of giving directly the solar vector, it is also possible to write a latitude and longitude with the date and time. Then, using calculation from (ASHRAE, 2009), the solar vector is computed.

It can be noted here that the atmosphere variables are transferred to the other models via the 'inner'/'outer' method.

\subsection{Wall model}

The wall model presented in Figure 2 is the thermal network between the cabin interior and the outside environment (all thermal components are from the MSL Thermal library).

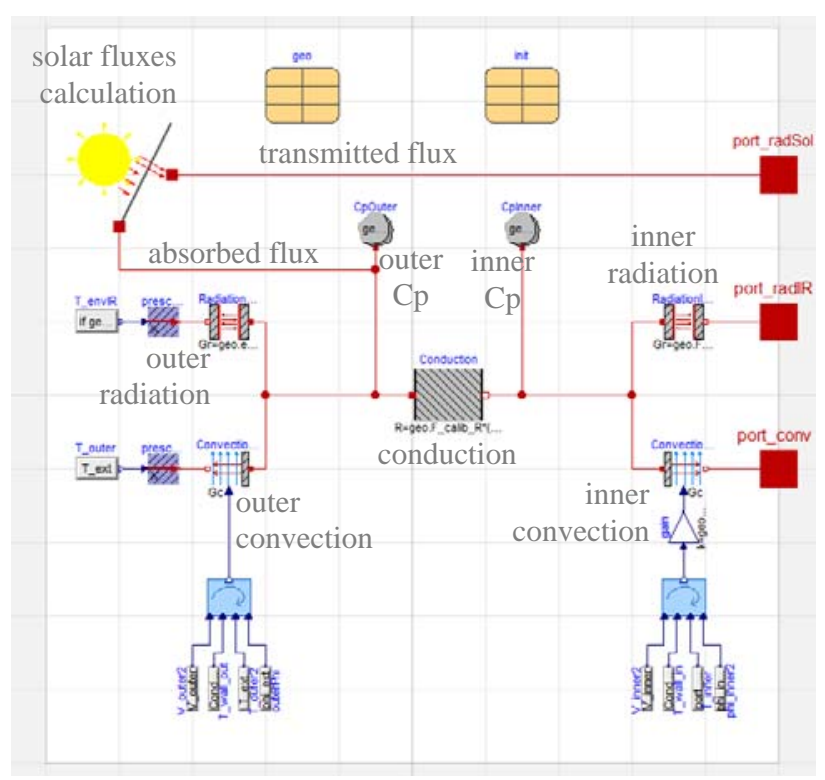

Figure 2. Wall model in DYMOLA.

Based on Figure 2, the thermal balance at the outer wall node $T_{\text {wall }}^{\text {out }}$ applies as follow (by convention, heat flow is positive when heat goes from outside into the cabin): 


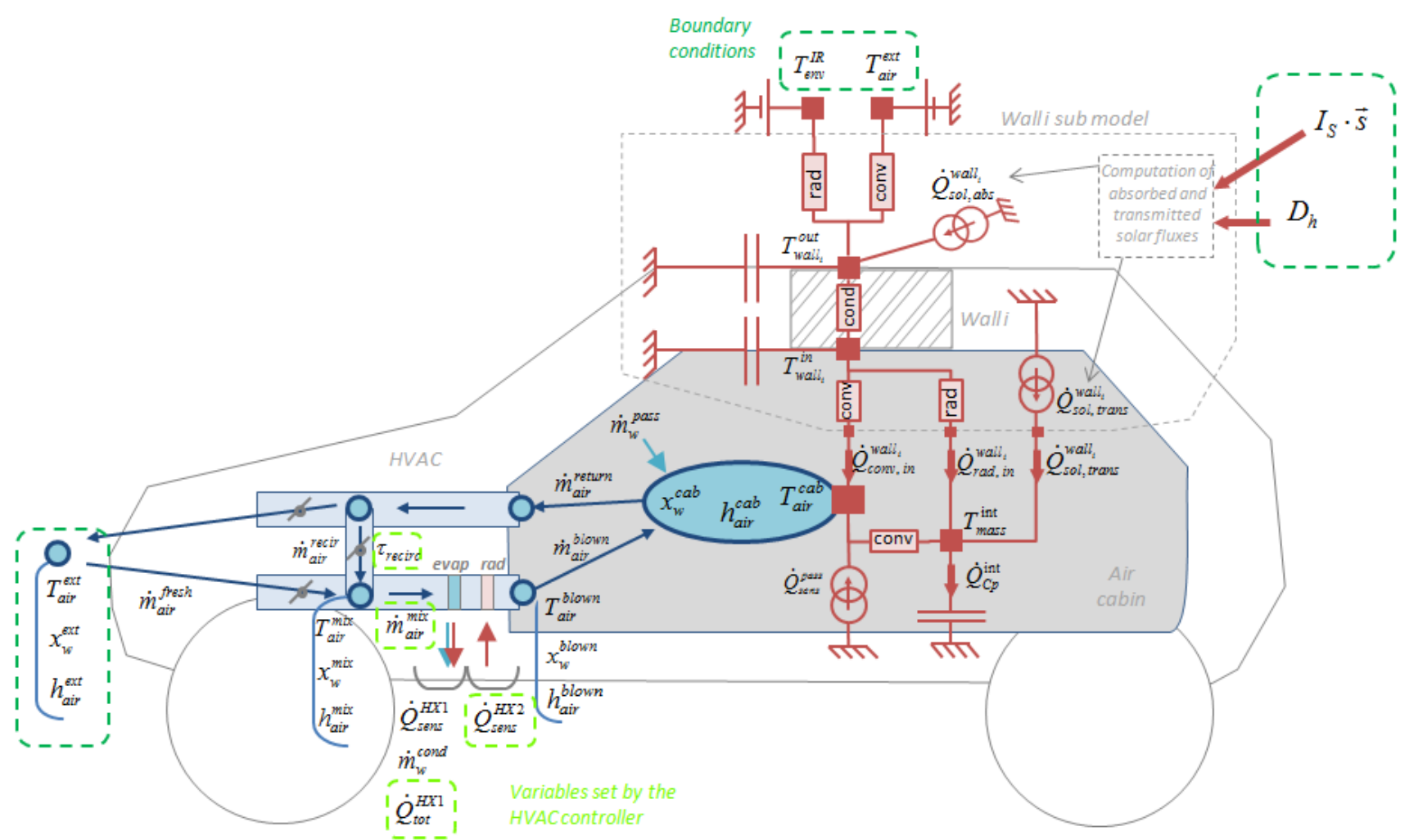

Figure 3. Schematic of the model.

$$
\begin{aligned}
& C_{\text {pout }}^{\text {wall }} \cdot \frac{d\left(T_{\text {wall }}^{\text {out }}\right)}{d t} \\
& =\dot{Q}_{\text {conv } \text { out }}^{\text {wall }}+\dot{Q}_{\text {rad,out }}^{\text {wall }}-\dot{Q}_{\text {cond }}^{\text {wall }}+\dot{Q}_{\text {sol,abs }}^{\text {wall }} \\
& =h_{\text {conv }}^{\text {out }} \cdot A_{\text {wall }} \cdot\left(T_{\text {air }}^{\text {ext }}-T_{\text {wall }}^{\text {out }}\right) \\
& +\varepsilon_{\text {wall }}^{\text {out }} \cdot A_{\text {wall }} \cdot \sigma \cdot\left(T_{\text {env }}^{R^{4}}-T_{\text {wall }}^{\text {out }}{ }^{4}\right) \\
& -\frac{1}{R_{\text {cond }}^{\text {wall }}} \cdot\left(T_{\text {wall }}^{\text {out }}-T_{\text {wall }}^{\text {in }}\right)+\dot{Q}_{\text {sol,abs }}^{\text {wall }}
\end{aligned}
$$

Similarly, the thermal balance at the inner wall node $T_{\text {wall }}^{\text {in }}$ is expressed as follow:

$$
\begin{aligned}
& C_{p \text { in }}^{\text {wall }} \cdot \frac{d\left(T_{\text {wall }}^{\text {in }}\right)}{d t} \\
& =\dot{Q}_{\text {cond }}^{\text {wall }}-\dot{Q}_{\text {conv } \text {,in }}^{\text {wall }}-\dot{Q}_{\text {rad,in }}^{\text {wall }} \\
& =\frac{1}{R_{\text {cond }}^{\text {wall }}} \cdot\left(T_{\text {wall }}^{\text {out }}-T_{\text {wall }}^{\text {in }}\right) \\
& -h_{\text {conv }}^{\text {in }} \cdot A_{\text {wall }} \cdot\left(T_{\text {wall }}^{\text {in }}-T_{\text {air }}^{\text {cab }}\right) \\
& -\varepsilon_{\text {wall }}^{\text {in }} \cdot F_{\text {wall-int }} \cdot A_{\text {wall }} \cdot \sigma \cdot\left(T_{\text {wall }}^{\text {in }}{ }^{4}-T_{\text {mass }}^{\text {int }}{ }^{4}\right)
\end{aligned}
$$

In eq. (1), the solar flux $\dot{Q}_{\text {sol,abs }}^{\text {wall }}$ is computed via a submodel described in section 2.4. In addition, the convection coefficient $h_{\text {conv }}^{\text {in }}$ and $h_{\text {conv }}^{\text {out }}$ are given in section 2.5. The wall thermal resistance $R_{\text {cond }}^{\text {wall }}$ and the thermal capacitances $C_{p \text { in }}^{\text {wall }}$ and $C_{p \text { out }}^{\text {wall }}$ are determined by basic calculations taking into account the multilayer structure of the wall. It is done in a generic way such that both opaque body (with an inner skin, a lining material and a outer skin) and glazing surfaces can be handled by the same model.

An interesting aspect here is that the radiation heat transfer has been considered both for inner and outer wall surfaces. The outer surface exchanges by radiation with a so called environment IR temperature $T_{e n v}^{I R}$. Determining this temperature is not trivial. Depending on the surfaces, it could be equal to the outside air temperature, but it also could be equal to the sky temperature, which can be far lower than the outside temperature for clear skies. In addition, during summer, the floor sees the road which can have a very high temperature compared to the air. In the model, those aspects are configurable. For the clear sky temperature, the correlation from (Swinbank, 1963) is used.

Furthermore, in eq. (2), one can observe that the internal radiative heat exchange is between the wall and the internal mass (the seats, the dashboard",...) via a view factor. First, this view factor is not easy to determine. In addition, the radiative heat exchanges between the walls themselves are not considered.

The impact of those different assumptions are evaluated in the results section. 


\subsection{Solar fluxes computation sub-model}

This sub-model included in the wall model aims at computing the absorbed solar flux $\dot{Q}_{\text {sol,abs }}^{\text {wall }}$ by the wall and the transmitted solar flux through the wall $\dot{Q}_{\text {sol,trans }}^{\text {wall }}$ (for glazing). The following equations, extracted from (ASHRAE, 2009) are used.

The direct solar flux $I_{n}$ received by a surface with a normal $\vec{n}$ is given by (with $p_{n s}$ the scalar product between the solar vector $\vec{s}$ and $\vec{n}$ and $I_{S}$ the solar flux):

$$
I_{n}=p_{n s} \cdot I_{s}
$$

Then, the total diffuse flux $D_{n}$ received is:

$$
D_{n}=D_{h} \cdot\left(\frac{1+\cos \theta}{2}\right)+\rho \cdot G_{h} \cdot\left(\frac{1-\cos \theta}{2}\right)
$$

With $D_{h}$ the horizontal diffuse flux, $\theta$ the angle between $\vec{n}$ and the vertical, $\rho$ the albedo and $G_{h}$ the global flux.

Finally, the solar fluxes are given by eq. (5) and (6).

$$
\begin{gathered}
\dot{Q}_{\text {sol,abs }}^{\text {wall }}=\alpha_{\text {sol }} \cdot A_{\text {wall }} \cdot\left(I_{n}+D_{n}\right) \\
\dot{Q}_{\text {sol, trans }}^{\text {wal }}=\tau_{\text {sol }} \cdot A_{\text {wall }} \cdot\left(I_{n}+D_{n}\right)
\end{gathered}
$$

\subsection{Convection sub-model}

The wall model also includes a convection sub-model. The convection in this thermal problem is quite complicated. Indeed, the geometry is complex and natural and forced convection can be mixed. A detailed analysis of the convection correlations has been conducted here.

First, it can be noted that the cabin walls are often assumed to be flat plates. Hence, the general correlations for flat plates (see (Bergman et al., 2011)) are often used. For instance, eq. (7) is for forced parallel and turbulent flow and eq. (8) is for natural convection over a vertical plate. All applicable flat plate correlations have been implemented in the code.

In addition, for internal convection, correlations of the form of eq. (9) (Abou Eid, 2016) and used in building applications have also been evaluated. The coefficients $c$ and $n$ are adjusted depending on the situations (floor, ceiling, vertical walls, mixed convection...).

Finally, for external correlations around the vehicle (car, bus or train), several authors (Fujita et al., 2001; Kataoka and Nakamura, 2001; Li and Sun, 2013; Mezrhab and Bouzidi, 2006; Zhang et al., 2009) use their own specific correlation in the general form of eq. (10) (with $a, b$ and $c$ constants). Most of the authors define a minimum value which is applied for low velocities.

$$
\begin{gathered}
N u_{L}=\left(0,037 \cdot \operatorname{Re}_{L}^{0.8}\right) \cdot \operatorname{Pr}^{1 / 3} \\
N u_{L}=\left(0.825+\frac{0,387 \cdot R a_{L}^{1 / 6}}{\left[1+(0.492 / \operatorname{Pr})^{9 / 16}\right]^{\beta / 27}}\right)^{2}
\end{gathered}
$$

$$
\begin{gathered}
h_{\text {conv }}=c \cdot\left|T_{\text {in }}^{\text {wall }}-T_{\text {air }}^{\text {cab }}\right|^{n} \\
h_{\text {conv }}=a+b \cdot v^{c}
\end{gathered}
$$

In order to give an idea on how the correlations compare, Error! Reference source not found. plots the computed coefficients. It appears that the general trends are similar except for the laminar correlations and Li's correlation. However, the coefficients can be multiplied by 1.5 from one correlation to the other. The impact of those correlations is evaluated in the result section. By default, the (Fujita et al., 2001) correlation and the eq. (9) with $c=3$ and $n=1 / 3$ (mixed convection) are used.

\subsection{Passenger model}

As shown in Figure 3, the model takes into account the passenger thermal loss $\dot{Q}_{\text {sens }}^{\text {pass }}$ and the passenger water vapor generation $\dot{m}_{w}^{\text {pass }}$. According to (ASHRAE, 2009), it is assumed that a person emits $70 \mathrm{~W}$ of sensible heat and $35 \mathrm{~W}$ of latent heat. The latent heat is converted to a mass flow rate in the model and not added in the thermal network. Only the mass flow rate is injected in the cabin volume and is then considered for the mass and energy balances. The number of passengers can be adjusted.

\subsection{Cabin model}

The cabin model is shown in Error! Reference source not found.. It includes the wall and passenger models that just have been presented. In the figure, only one wall model appears. However, an important feature here is that it is actually a vector of walls. Thus, the number of walls, opaque or transparent walls, can be varied. This allows adjusting to the exact vehicle configuration.

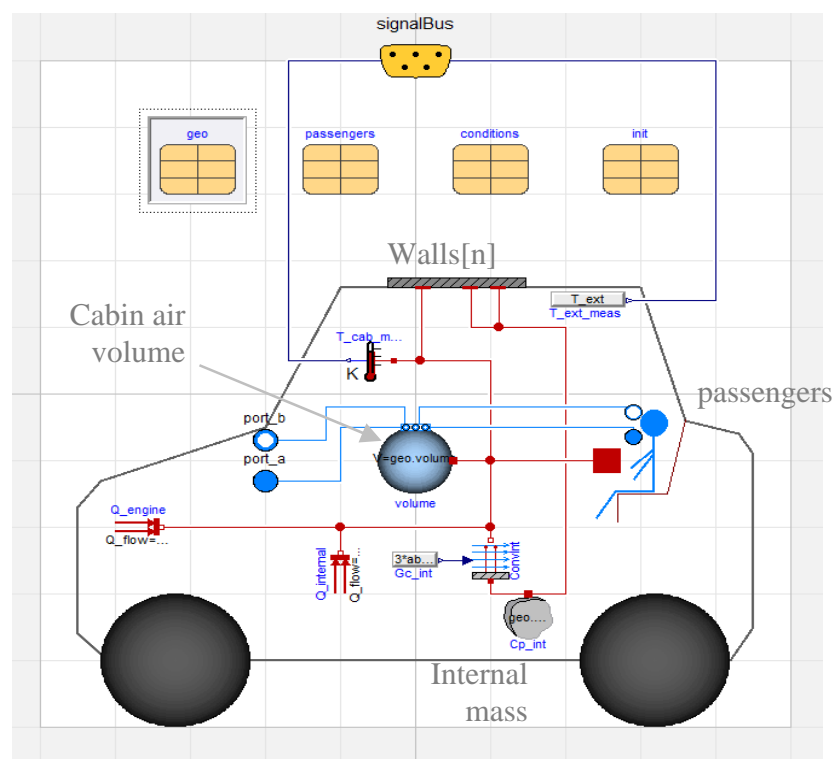

Figure 4. Cabin model in DYMOLA. 

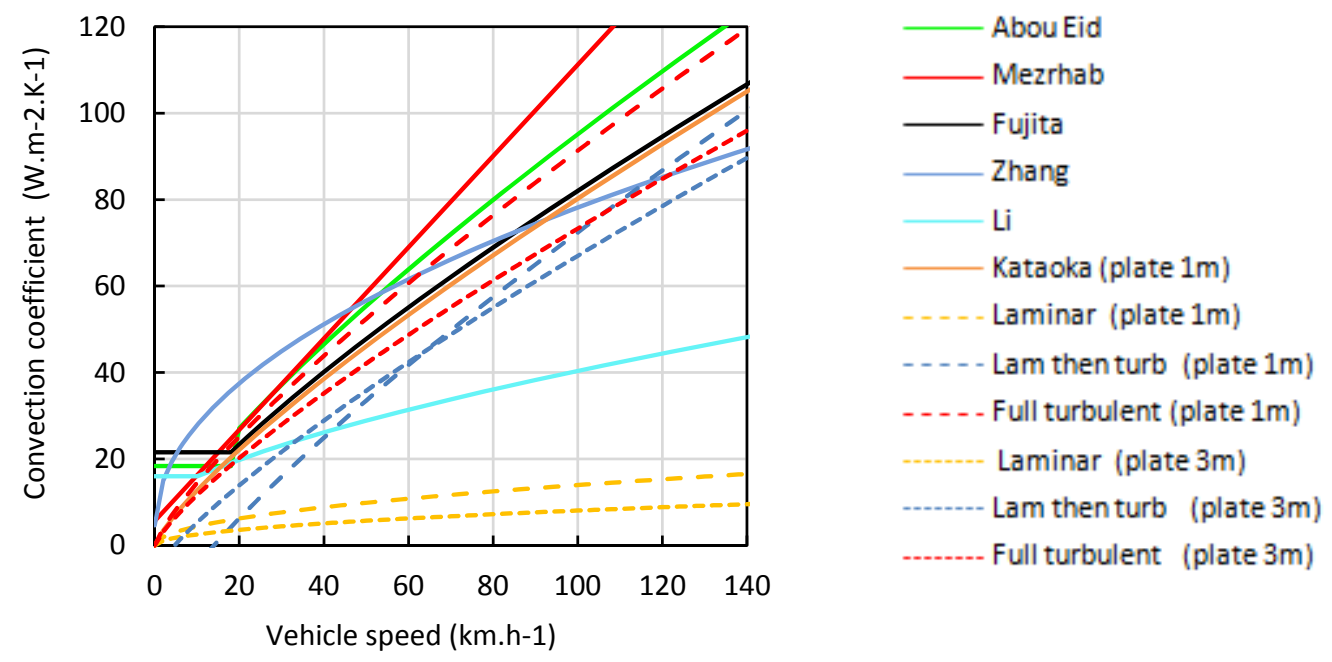

Figure 5. Convection coefficients from the different correlations for external forced convection.

In this model, the energy balance applies for the internal mass node $T_{\text {mass }}^{\text {int }}$ :

$$
\begin{gathered}
C_{p}^{\text {int }} \cdot \frac{d\left(T_{\text {mass }}^{\text {int }}\right)}{d t}= \\
\dot{Q}_{\text {conv }}^{\text {int }}+\sum_{i=1}^{n W a l l}\left(\dot{Q}_{{\text {sol }, \text { trans }_{i}}_{\text {wall }}}^{\text {nWa } \text {, in }}\right)
\end{gathered}
$$

With :

$$
\dot{Q}_{\text {conv }}^{\text {int }}=h_{\text {conv }}^{\text {int }} \cdot A_{\text {mass }} \cdot\left(T_{\text {air }}^{\text {cab }}-T_{\text {mass }}^{\text {int }}\right)
$$

An assumption that can be discussed here is the approach with the internal mass and the way the radiation problem is treated. It follows the approach used in (Marcos et al., 2014) where a "base" node is defined. The internal mass is assumed to be a black body and to receive all the radiation heat fluxes: the solar transmitted flux as well as the IR flux from the inner surface of the walls. It is useful to consider this internal mass since it has a strong impact on transient results. In addition, due to the complex shape of the internal masses and their high emissivity and absorptivity, it makes sense to assume a black body here. Those points are discussed in the result section.

Then, the energy balance is applied to the air volume:

$$
\begin{aligned}
& V_{\text {air }}^{\text {cab }} \cdot\left(u_{\text {air }}^{\text {cab }} \cdot \frac{\partial \rho_{\text {air }}^{\text {cab }}}{\partial t}+\rho_{\text {air }}^{\text {cab }} \cdot \frac{\partial u_{\text {air }}^{\text {cab }}}{\partial t}\right) \\
& =\dot{m}_{\text {air }}^{\text {blown }} \cdot h_{\text {air }}^{\text {blown }}-\dot{m}_{\text {air }}^{\text {return }} \cdot h_{\text {air }}^{\text {cab }} \\
& +\dot{m}_{w}^{\text {pass }} \cdot h_{w, v a p}^{37^{\circ} C}+\dot{Q}_{\text {sens }}^{\text {pass }} \\
& +\sum_{i=1}^{n \text { Wall }} \dot{Q}_{\text {conv }, i n}^{\text {wall }}-\dot{Q}_{\text {conv }}^{\text {int }}
\end{aligned}
$$

With $h_{w, v a p}^{37^{\circ} \mathrm{C}}$ the enthalpy of water vapor at $37^{\circ} \mathrm{C}$.
In addition to the energy balance, the mass balances also apply:

$$
\begin{gathered}
V_{\text {air }}^{\text {cab }} \cdot \frac{\partial\left(\rho_{\text {air }}^{\text {cab }}\right)}{\partial t}= \\
\dot{m}_{\text {air }}^{\text {blown }}-\dot{m}_{\text {air }}^{\text {return }}+\dot{m}_{w}^{\text {pass }} \\
V_{\text {air }}^{\text {cab }} \cdot\left(x_{w}^{\text {cab }} \cdot \frac{\partial \rho_{\text {air }}^{\text {cab }}}{\partial t}+\rho_{\text {air }}^{\text {cab }} \cdot \frac{\partial x_{w}^{\text {cab }}}{\partial t}\right)= \\
\dot{m}_{\text {air }}^{\text {blown }} \cdot x_{w}^{\text {blown }}-\dot{m}_{\text {air }}^{\text {return }} \cdot x_{w}^{\text {cab }}+\dot{m}_{w}^{\text {pass }}
\end{gathered}
$$

A key point here is of course the water vapor mass balance which will determine the humidity ratio in the cabin air and impact the HVAC either by requiring additional fresh air to avoid mist and/or by adding a cooling load to the evaporator.

\subsection{HVAC model}

The HVAC can be seen as an external component of the cabin. Therefore, one could want to focus on the cabin and not to consider at all the HVAC for the determination of thermal cabin needs. However, considering the HVAC is actually required here to properly compute the thermal cabin needs, which translate into the HVAC thermal loads. Indeed, knowing the water vapor condensation rate at the evaporator is important since it can strongly impact the total $\mathrm{A} / \mathrm{C}$ needs. Moreover, this condensation rate is required when addressing the cabin dehumidification needs, which also translate into cabin needs. In addition, the thermal needs are strongly dependant on the recirculation ratio, which is controlled by the HVAC.

Figure 6 is a view of the HVAC model. It is composed of a recirculation box and a cooling/heating element. The recirculation box is made of valves (from MSL Fluid library) whose openings are adjusted to 
control the recirculation ratio as desired (a PI is used here in the controller of the Figure 1). The model handles the mixing of the fresh air with the recirculated air via basic mass and energy balances.

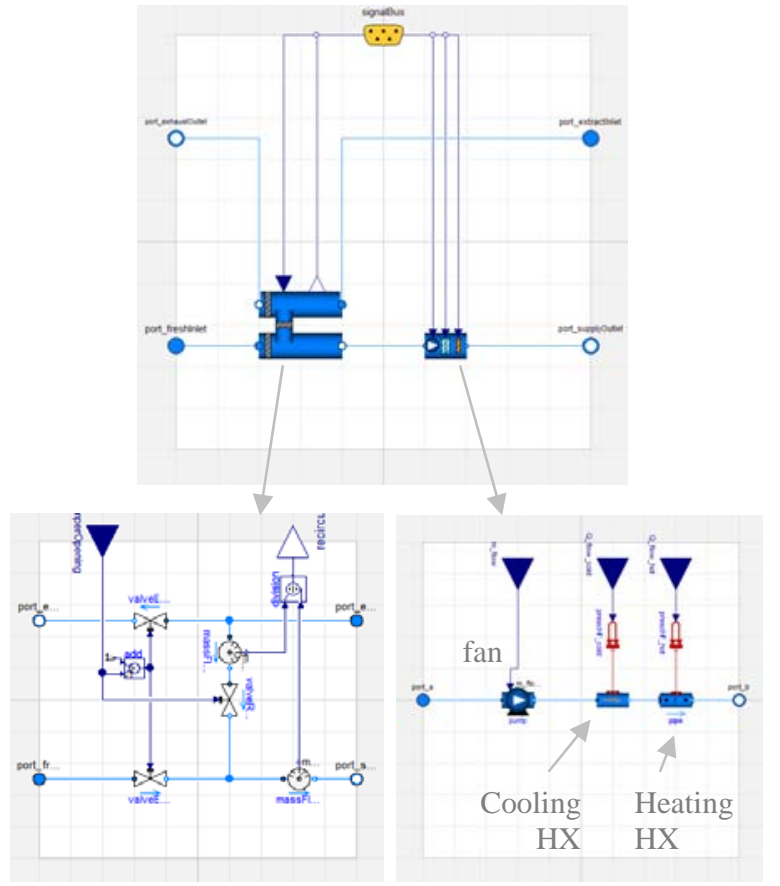

Figure 6. HVAC model in DYMOLA.

The cooling/heating element is composed of a fan, a cooling HX and a heating HX. The fan model is the 'PrescribedPump' model from MSL Fluid library and the heating HX is modeled with a 'DynamicPipe' from the same library. Only the cooling HX is modeled via an ad hoc pipe which is able to handle water vapor condensation. To do so, the sensible heat exchange $\dot{Q}_{\text {sens }}^{\text {evap }}$ is computed as follow:

$$
\begin{aligned}
\dot{Q}_{\text {sens }}^{\text {evap }}=h_{\text {conv }}^{\text {evap }} & \cdot A_{\text {evap }} \\
& \cdot\left(\frac{T_{\text {air }}^{\text {mix }}-T_{\text {air }}^{\text {evap out }}}{\ln \left(\frac{T_{\text {air }}^{\text {mix }}-T_{H X i}^{\text {wall }}}{T_{\text {air }}^{\text {evaut }}-T_{H X i}^{\text {wall }}}\right)}\right)
\end{aligned}
$$

Then, the water vapor condensation rate $\dot{m}_{w}^{\text {cond }}$ is given by (when $x_{\text {air }}^{\text {mix }}>x_{\text {sat }}\left(T_{\text {evap }}^{\text {wall }}\right)$; null otherwise):

$$
\begin{aligned}
& \dot{m}_{w}^{\text {cond }}=\frac{h_{\text {conv }}^{\text {evap }} \cdot A_{\text {evap }}}{\rho_{\text {air }}^{\text {mix }} \cdot c_{p, \text { air }}} \\
& \left.\cdot\left(\frac{x_{\text {air }}^{\text {mix }}-x_{\text {air }}^{\text {blown }}}{\ln \left(\frac{x_{\text {air }}^{\text {mix }}-x_{\text {sat }}\left(T_{\text {evap }}^{\text {wall }}\right)}{x_{\text {air }}^{\text {blown }}-x_{\text {sat }}\left(T_{\text {evap }}^{\text {wall }}\right)}\right)}\right)\right)
\end{aligned}
$$

Then, it comes:

$$
\dot{Q}_{\text {tot }}^{\text {evap }}=\dot{Q}_{\text {sens }}^{\text {evap }}+\dot{m}_{w}^{\text {cond }} \cdot L_{l v}
$$

At this point it can be noted that the controller of the HVAC (see Figure 1) can adjust the evaporator sensible cooling power and the heating power to obtain proper cabin air temperature and humidity (and hence to satisfy the cabin needs: (heating, cooling, dehumidifying). It is also possible to impose both sensible cooling power and heating power. Then, using eqs. (16) to (18), the $T_{\text {evap }}^{\text {wall }}$ is computed followed by $\dot{m}_{w}^{\text {cond }}$ and $\dot{Q}_{\text {tot }}^{\text {evap }}$.

Here, it can be noted that the heat-pickup (or loss) in the air distribution system (dashbord and recircirculation channel) has been neglected.

\subsection{Model parameters}

The model requires a full list of parameters. There are not presented in detail here due to conciseness considerations. Basically, the car geometry is described by the wall areas and orientations. In addition, thicknesses and thermal parameters are required. For the following results, parameters from a mid-size car are applied (main parameters given in Table 1).

Table 1. Geometry and thermal parameters.

\begin{tabular}{|l|l|}
\hline Parameter & Value \\
\hline Glazing areas & $2 \mathrm{~m}^{2}$ \\
\hline Opaque areas & $9.9 \mathrm{~m}^{2}$ \\
\hline Lateral insulation thickness & $75 \mathrm{~mm}$ \\
\hline Floor insulation thickness & $15 \mathrm{~mm}$ \\
\hline Roof insulation thickness & $13 \mathrm{~mm}$ \\
\hline Internal thermal capacity & $75 \mathrm{~kJ} . \mathrm{K}^{-1}$ \\
\hline Total wall thermal capactity & $155.4 \mathrm{~kJ} . \mathrm{K}^{-1}$ \\
\hline Glazing transmittivity & 0.85 \\
\hline Wall outer absorptivity & 0.85 \\
\hline
\end{tabular}

In addition to those parameters, when one wants to compute the cabin thermal needs, operating condition parameters are required. Those parameters are presented in Table 2. As we will see, some of those parameters strongly influence the results. They are in a sense arbitrary and depend more on the manufacturer philosophy (specifications), but they have to be carefully considered by one who wants to study thermal needs due to their strong influence.

In addition to the parameters given in Table 2, the target cabin temperature is set to $23^{\circ} \mathrm{C}$. The number of passengers is 0 for heating and 4 for AC. No sun is considered for heating and the sun is defined by $I_{S}=$ $700 \mathrm{~W} \cdot \mathrm{m}^{-2}$ and $D_{h}=117 \mathrm{~W} \cdot \mathrm{m}^{-2}$ for $\mathrm{A} / \mathrm{C}$. The vehicle speed is set to $45 \mathrm{~km} / \mathrm{h}$. And the initial condition is a cabin at $T_{\text {air }}^{\text {ext }}$ (all thermal nodes). 
Table 2. Operating conditions.

\begin{tabular}{|c|c|c|c|c|c|c|}
\hline$T_{\text {air }}^{\text {ext }}$ & $\varphi$ & $t_{\text {targ }}$ & $\begin{array}{c}\dot{m}_{\text {air }}^{\text {blown }} \\
\text { Stab. }\end{array}$ & $\begin{array}{c}\dot{m}_{\text {air }}^{\text {blown }} \\
\text { Conv. }\end{array}$ & $\dot{m}_{\text {air }}^{\text {fresh }}$ & $\begin{array}{l}\text { Deshum. } \\
\Delta T_{\text {air }}^{\text {evap }}\end{array}$ \\
\hline$\left({ }^{\circ} \mathrm{C}\right)$ & $\%$ & $\min$ & $\left(\mathrm{kg} \mathrm{h}^{-1}\right)$ & $\left(\mathrm{kg} \cdot \mathrm{h}^{-1}\right)$ & $\left(\mathrm{kg} \cdot \mathrm{h}^{-1}\right)$ & $\left({ }^{\circ} \mathrm{C}\right)$ \\
\hline-20 & \multirow{2}{*}{85} & \multirow{4}{*}{20} & 245 & 400 & \multirow{5}{*}{$\begin{array}{c}\text { Same } \\
\text { as } \\
\dot{m}_{\text {air }}^{\text {blown }}\end{array}$} & \multirow{5}{*}{ No } \\
\hline-15 & & & 236 & 390 & & \\
\hline-10 & \multirow{7}{*}{95} & & 225 & 360 & & \\
\hline-5 & & & 210 & 330 & & \\
\hline $\mathbf{0}$ & & \multirow{2}{*}{15} & 200 & 310 & & \\
\hline 5 & & & 185 & 290 & \multirow{4}{*}{$\begin{array}{l}\text { (no } \\
\text { recirc) }\end{array}$} & 3 \\
\hline 10 & & \multirow{3}{*}{10} & 180 & 285 & & 5 \\
\hline 15 & & & 187 & 290 & & \multirow{2}{*}{10} \\
\hline 20 & & & 195 & 300 & & \\
\hline 15 & \multirow{3}{*}{95} & \multirow{4}{*}{10} & 187 & 290 & 187 & \multirow{2}{*}{$\min 10$} \\
\hline 20 & & & 195 & 300 & 195 & \\
\hline 25 & & & 248 & 390 & 124 & \multirow{5}{*}{ N/A } \\
\hline 30 & 85 & & 330 & 533 & 88 & \\
\hline 35 & 65 & \multirow{2}{*}{15} & 378 & 608 & 59 & \\
\hline 40 & 55 & & 400 & 632 & \multirow{2}{*}{48} & \\
\hline 45 & 35 & 20 & 408 & 640 & & \\
\hline
\end{tabular}

\subsection{Model validation}

The experimental validation of the model is being carried out at the moment. Hence, the results were not available for this paper but they will be presented in a following paper. The first tests conducted with a crane cabin (and not a car cabin, due to industrial partner needs) were very encouraging since the cabin temperature was predicted within $+/-1^{\circ} \mathrm{C}$. The first tests suggested that the thermal parameters need to be filled carefully and that the analysis conducted in this paper are valid.

\section{Model results}

\subsection{Reference cases - steady state}

To start the analysis, let's have look at the thermal loads at $0^{\circ} \mathrm{C}$ and $40^{\circ} \mathrm{C}$ (the other parameters are as given in section 2.9 ) in steady state.

Figure 7 presents the thermal loads at $0^{\circ} \mathrm{C}$. The total heating need is $2.3 \mathrm{~kW}$. It can be observed that the fresh air is responsible for more than half of the needs. Then, the heat transfer occurs more through glazing.

For the air-conditioning case at $40^{\circ} \mathrm{C}$ presented in Figure 8 , the load split is more complex. The total cooling load is $2.9 \mathrm{~kW} .1 / 3$ is due to the solar, $1 / 3$ due to fresh air and the last third due to heat exchange with the exterior temperature through wall and due to the passengers. Because the recirculation ratio is high, the fresh air sensible load is low. However, the high humidity level results in an important fresh air latent load. It is important to take into account this load since the $\mathrm{A} / \mathrm{C}$ system will have to overcome it.

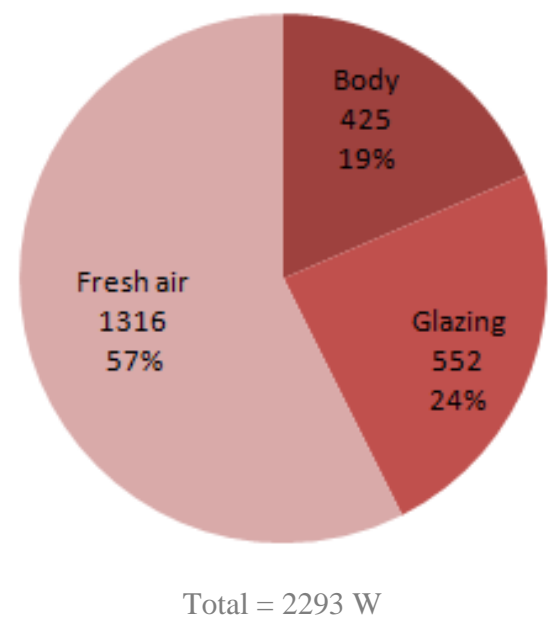

Figure 7. Thermal loads (W) at $0^{\circ} \mathrm{C}$.

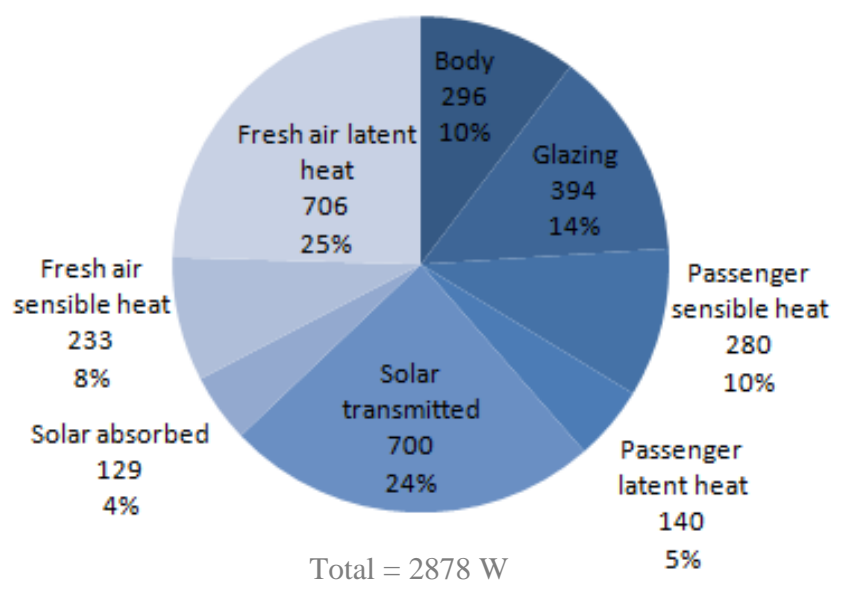

Figure 8. Thermal loads (W) at $40^{\circ} \mathrm{C}$.

\subsection{Sensitivities - steady state}

In this section different assumptions were varied for the two reference cases (at $0^{\circ} \mathrm{C}$ and $40^{\circ} \mathrm{C}$ ).

First, the different correlations presented in section 2.5 were tested. Using flat plate natural convection correlation for the internal surfaces can decrease by $10 \%$ the thermal needs. For external surfaces, the sensitivity to the correlations is less than $+/-3 \%$.

Several cases were tested to evaluate the dependence on radiative assumptions. The IR environment temperatures have been assumed to be all the sky temperature or all the outside air temperature. A case with a road at $80^{\circ} \mathrm{C}$ has also been considered. The view factors between each wall and the internal mass have been varied from default value to 1 . For all those cases, the sensitivity was less than $+/-3 \%$. A case with no radiative heat exchange inside the cabin has been considered. It decreased by $7 \%$ the thermal heating need and 5\% the cooling needs for the reference case using the mixed convection correlation for the inner convection. However, if pure natural 
convection conditions prevail, neglecting the inner radiation decreases by $17 \%$ the heating and cooling needs. Hence, internal radiation needs to be taken into account.

The impacts of the conditions selected in section 2.9 have also been analyzed via the following cases:

- Case 1: 25\% increase in blown air flow rate (with same recirculation rate as default case)

- Case 2: recirculation rate at $50 \%$

- Case 3: target cabin temperature set at $20^{\circ} \mathrm{C}$

- Case 4: stationary vehicle

The results are presented in Table 2. It is clear that those operating conditions have strong impacts on the results, far more important than the majority of previous modeling sensitivities. Therefore, it means that, when talking about the cabin needs, the related considered conditions should be clearly stated, particularly the recirculation rate considered and the blown air flow rate.

Table 3. Sensitivities to operating conditions

\begin{tabular}{|c|c|c|c|c|}
\hline \multicolumn{5}{|c|}{ Thermal needs (W) and relative gap (\%). } \\
\hline Text & Case 1 & Case 2 & Case 3 & Case 4 \\
\hline \multirow{2}{*}{$0^{\circ} \mathrm{C}$} & 2622 & 1638 & 1982 & 2079 \\
& $\mathbf{1 4 . 3 \%}$ & $\mathbf{- 2 8 . 6 \%}$ & $\mathbf{- 1 3 . 6 \%}$ & $\mathbf{- 9 . 3 \%}$ \\
\hline \multirow{2}{*}{$40^{\circ} \mathrm{C}$} & 2786 & 4126 & 3102 & 2937 \\
& $\mathbf{- 3 . 2 \%}$ & $\mathbf{4 3 . 4 \%}$ & $\mathbf{7 . 8 \%}$ & $\mathbf{2 . 1 \%}$ \\
\hline
\end{tabular}

\subsection{Cabin needs - steady state}

The thermal cabin needs in steady state conditions are presented in Figure 9. Between 5 and $20^{\circ} \mathrm{C}$, the dehumidification (cooling and heating at the same time) is taken into account.

Based on the previous discussion, needs for varied recirculation ratio from 0 to $100 \%$ is added to the curves (without taking into account dehumidification needs). It corresponds to the grey bands.

For the dehumidification zone, the required heating is between 1 to $2 \mathrm{~kW}$. Then, at $-10^{\circ} \mathrm{C}$, it increases up to $3.6 \mathrm{~kW}$. Those numbers are the same order of magnitude as the average traction power for an urban trip (taking into account stops), though lower. Thus, it appears clearly here why the heating is so damageable for electric vehicle range for a basic case using electric heaters. The A/C needs are also high but the they increase less with respect to the temperature above $25^{\circ} \mathrm{C}$ because of the high recirculation ratio considered and the $\mathrm{A} / \mathrm{C}$ system has a better COP then the electric heaters.

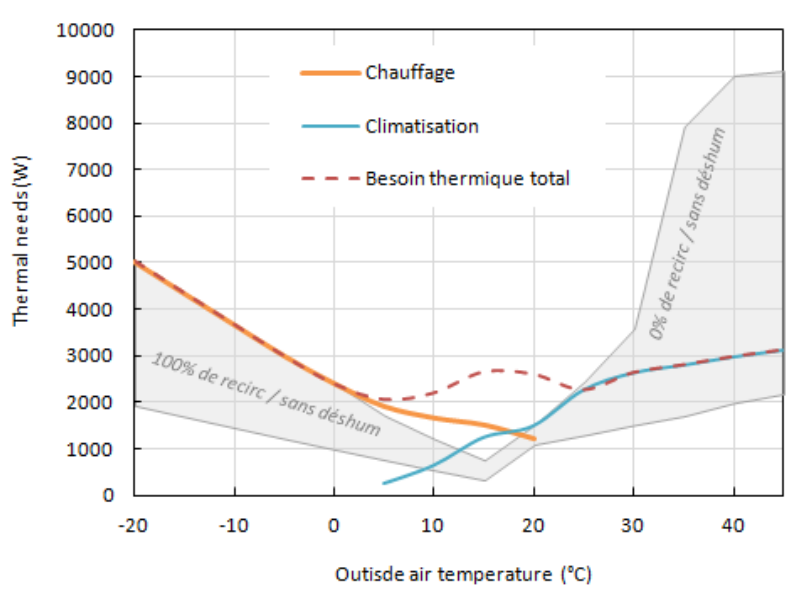

Figure 9. Steady state thermal needs.

\subsection{Reference cases - convergence}

Similarly to what has been done for steady state, two reference cases, based on operating conditions described in section 2.9 at $0^{\circ} \mathrm{C}$ and $40^{\circ} \mathrm{C}$, are analyzed. Figure 10 is a plot of the cabin air temperature during the warm-up. $4 \mathrm{~kW}$ heating is required to reach the targeted temperature within the targeted duration. The heating power is applied continuously during the simulation and that is why the temperature exceeds the target at the end of the simulation. For normal cases, once the targeted temperature is reached within a certain interval, a real HVAC control algorithm would decrease the thermal power and converge approximately towards the steady state required power (values presented previously). Here, the controller is not modeled in details and just a constant-power transient is analyzed.

The results for the cool-down at $40^{\circ} \mathrm{C}$ are presented in Figure 11. Here, $3.5 \mathrm{~kW}$ were required to reach the proper temperature within the required duration.

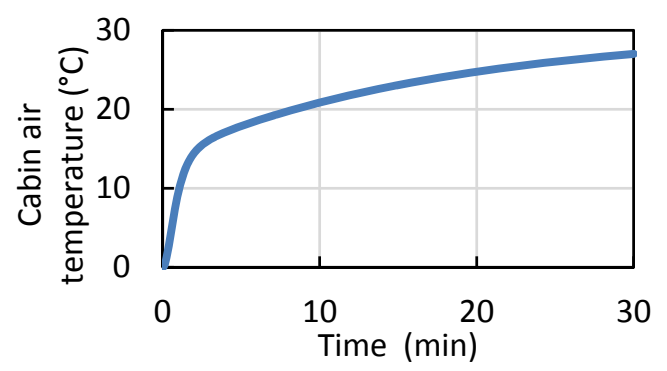

Figure 10. Warm-up transient cabin air temperature.

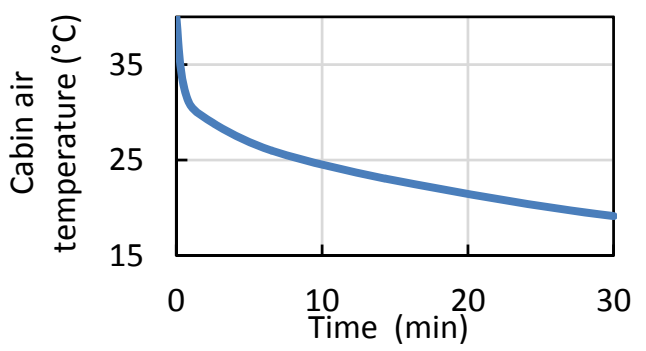

Figure 11. Cool-down transient cabin air temperature. 
A rapid change of slope can be observed on both curves. It separates two transient phases. The first one corresponds to the air capacity and the second one to the wall and internal capacities. This separation is not so obvious in practice since the HVAC power also integrates a transient phase, which smoothes the curves.

\subsection{Sensitivities - convergence}

A sensitivity analysis with regards to the thermal capacitances has been conducted. It appears that the internal mass has 3 times more influence than the wall capacitances, but the dependency is not so important since an increase by $50 \%$ of the internal mass capacitance results in an increased less than $7.5 \%$ of the required power.

On the other hand, the assumption with an internal mass separated from the air cabin by a convection resistance has been analyzed. Integrating directly the internal mass capacitance to the air (i.e. without convection resistance) increases by $9 \%$ and $28 \%$ respectively the heating needs and the cooling needs. In addition, if the inner radiative couplings are considered between the walls and the air (instead of between the walls and the internal mass), the cooling needs are increased by $15 \%$. Of course, those two approaches do not represent the reality, but this analysis emphasizes the fact that the internal mass has to be considered properly.

Furthermore, a sensitivity analysis on the conditions given in Table 2 is conducted with the following cases:

- Case 1: targeted temperature at the end of the convergence $2^{\circ} \mathrm{C}$ lower than steady state.

- Case 2: required duration to reach proper cabin temperature is 10 min instead of 15 min initially.

- Case 3: initial condition: vehicle parked under sun (and so initial cabin temperatures higher than outside temperature).

Results are presented in Table 3. The two first cases have impacts around $10 \%$. On the other hand, taking into account a case with the cabin under sun for hot cases increased by more than $40 \%$ the thermal needs.

Table 4. Sensitivities to operating conditions.

\begin{tabular}{|c|c|c|c|}
\hline \multicolumn{4}{|c|}{ Thermal needs (W) and relative gap (\%). } \\
\hline Text & Case 1 & Case 2 & Case 3 \\
\hline $0^{\circ} \mathrm{C}$ & $-10.0 \%$ & $12.5 \%$ & N/A \\
\hline $40^{\circ} \mathrm{C}$ & $-8.6 \%$ & $8.6 \%$ & $42.9 \%$ \\
\hline
\end{tabular}

\subsection{Cabin needs - convergence}

The thermal needs for convergence are presented in Figure 12. In addition to the 'with or without recirculation' grey band, a point at $40^{\circ} \mathrm{C}$ corresponding to the case with a parked vehicle under the sun is added since it increases a lot the needs.
For the convergence mode, the heating needs are roughly twice the needs for the steady state mode. The increase is less important for the cooling needs.

Those results suggest that, for an electric vehicle, the usage will have a strong influence on the thermal needs and, thus, on the vehicle range. Indeed, if the vehicle is used only for urban trip, short distances but lots of time at low speed or even stopped, the HVAC consumption will be high due to convergence mode.

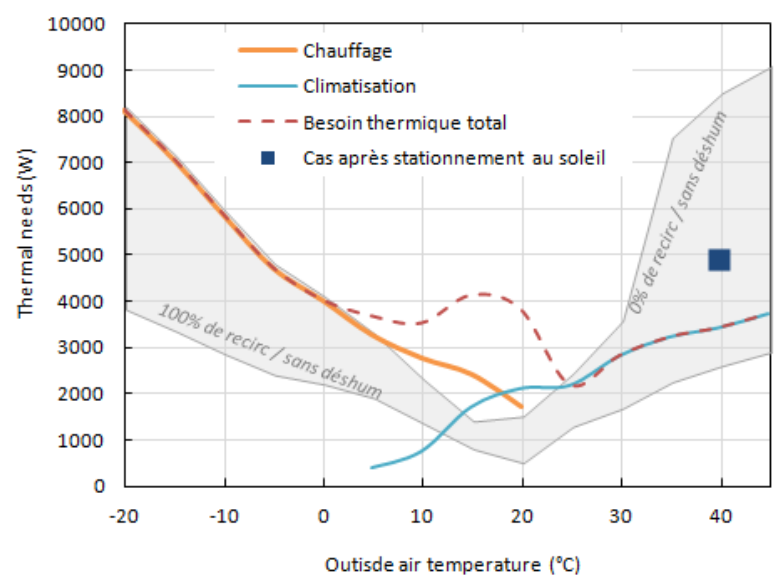

Figure 12. Convergence thermal needs

\section{Conclusion}

A transient thermal model of a vehicle cabin has been developed. Different model assumptions have been discussed and analyzed. The results showed that the model is not so sensitive to some non trivial modeling aspects such as the convective correlations. However, it appeared that neglecting the inner radiation or the internal thermal node can have an important impact in some cases (up to 15 to $25 \%$ approximately). On the other hand, it appeared that, if one wants to determine the thermal cabin needs, the considered arbitrary conditions actually dramatically influence the results. In addition, it is important to consider the dehumidification needs and the latent heat generated in the evaporator.

The model allowed establishing the thermal needs for the steady state case as well as for the convergence mode. The heating needs for the convergence mode are roughly twice the needs for the steady state mode. In addition, the thermal needs are of the same order of magnitude as the traction needs. The results clearly indicate that the thermal needs are damageable for electric vehicle range, particularly the heating, and that the vehicle usage is determinant.

In future work, the proposed model will be integrated in an electric vehicle model in order to study different thermal strategies such as the use of a heat pump, pre-conditioning and thermal storage. The model can also be used to evaluate improved cabin thermal design. 


\section{Acknowledgements}

This work received financial support from the French National Research Agency (ANR) under the ELEC-HP project (grant number ANR-11-VPTT-005).

\section{Nomenclature}

\begin{tabular}{|c|c|}
\hline Symbol & Name [unit] \\
\hline$A$ & Area $\left[\mathrm{m}^{2}\right]$ \\
\hline$C_{p}$ & Specific heat $\left[\mathrm{J}^{\mathrm{K}} \mathrm{K}^{-1} \cdot \mathrm{kg}^{-1}\right]$ \\
\hline$F$ & View factor [-] \\
\hline$h$ & Enthalpy per unit mass $\left[{\left.\mathrm{J} . \mathrm{kg}^{-1}\right]}^{-1}\right.$ \\
\hline$L$ & Length $[\mathrm{m}]$ \\
\hline$L_{l v}$ & Latent heat of vaporization $\left[\mathrm{J} \mathrm{kg}^{-1}\right]$ \\
\hline$\dot{m}$ & Mass flow rate $\left[\mathrm{kg} . \mathrm{s}^{-1}\right]$ \\
\hline $\mathrm{Nu}$ & Nusselt number [-] \\
\hline $\operatorname{Pr}$ & Prandtl number [-] \\
\hline$\dot{Q}$ & Heat transfer rate [W] \\
\hline$R$ & Thermal resistance $\left[{\left.\mathrm{K} . \mathrm{W}^{-1}\right]}^{-1}\right.$ \\
\hline$R a$ & Rayleigh number \\
\hline$R e$ & Reynolds number [-] \\
\hline$T$ & Temperature [K] \\
\hline$t$ & Time $[\mathrm{s}]$ \\
\hline$u$ & Internal energy per mass $\left[\mathrm{J}^{\mathrm{kg}}{ }^{-1}\right]$ \\
\hline$V$ & Volume $\left[\mathrm{m}^{3}\right]$ \\
\hline$v$ & Velocity $\left[\mathrm{m} . \mathrm{s}^{-1}\right]$ \\
\hline$x_{i}$ & $\begin{array}{l}\text { Mass ratio of the species } i \text { in a } \\
\text { mixture }\left[\mathrm{kg}^{\left.-\mathrm{kg}^{-1}\right]}\right.\end{array}$ \\
\hline
\end{tabular}

\section{Greek symbols}

$\begin{array}{ll}\alpha & \text { Absorptivity [-] } \\ \varphi & \text { Relative humidity [-] } \\ \varepsilon & \text { Emissivity [-] } \\ \rho & \left.\text { Density [kg. }{ }^{-3}\right] \\ \sigma & \text { Stefan's constant [-] } \\ \tau & \text { Recirculation [-] or transmissivity [-] }\end{array}$

Subscripts or Superscripts

$\begin{array}{ll}\text { abs } & \text { Absorbed } \\ \text { air } & \text { Related to moist air } \\ \text { blown } & \text { Blown } \\ \text { cab } & \text { Cabin } \\ \text { cond } & \text { Conduction } \\ \text { conv } & \text { Convection }\end{array}$

$\begin{array}{ll}\text { env } & \text { Environment } \\ \text { evap } & \text { Evaporator } \\ \text { ext } & \text { Exterior } \\ \text { IR } & \text { Infrared } \\ \text { In } & \text { Inner side } \\ \text { HX } & \text { Heat exchanger } \\ \text { mix } & \text { Mixed } \\ \text { out } & \text { Outer side } \\ \text { pass } & \text { Passengers } \\ \text { return } & \text { Return } \\ \text { sat } & \text { Saturation } \\ \text { sol } & \text { Solar } \\ \text { trans } & \text { Transmitted } \\ \text { w } & \text { Related to water } \\ \text { wall } & \text { At or through wall surface }\end{array}$

\section{References}

Abou Eid, R., 2016. Rapport - Passenger comfort and HVAC thermal load in a tramway.

Al-Kayiem, H.H.., Sidik, F.B.M.., Munusammy, Y.R.. A.. L., 2010. Study on the Thermal Accumulation and Distribution Inside a Parked Car Cabin. Am. J. Appl. Sci. 7, 784-789.

ASHRAE, 2009. ASHRAE Handbook-Fundamentals.

Bergman, T.L., Lavine, A.S., Incropera, F.P., Dewitt, D.P., 2011. Fundamentals of Heat and Mass Transfer, 6th ed. John Wiley \& Sons.

Boukhris, Y., Gharbi, L., Ghrab-Morcos, N., 2009. Modeling coupled heat transfer and air flow in a partitioned building with a zonal model: Application to the winter thermal comfort. Build. Simul. 2, 67-74. doi:10.1007/S12273-009-9405-8

Daoud, A., Galanis, N., 2008. Prediction of airflow patterns in a ventilated enclosure with zonal methods. Appl. Energy 85, 439-448. doi:10.1016/j.apenergy.2007.10.002

Fujita, A., Kanemaru, J. ichi, Nakagawa, H., Ozeki, Y., 2001. Numerical simulation method to predict the thermal environment inside a car cabin. JSAE Rev. 22, 39-47. doi:10.1016/S0389-4304(00)00101-6

Inard, C., Bouia, H., Dalicieux, P., 1996. Prediction of air temperature distribution in buildings with a zonal model. Energy Build. 24, 125-132. doi:10.1016/03787788(95)00969-8

Iskandar, B.S., 2010. Study on the Thermal Accumulation and Distribution Inside a Parked Car Cabin Hussain $\mathrm{H}$ . Al-Kayiem , M . Firdaus Bin M . Sidik and Yuganthira R . A . L Munusammy Department of Mechanical Engineering , University Technology PETRONAS ,. Ashrae Stand. 7, 784-789.

Kataoka, T., Nakamura, Y., 2001. Prediction of thermal sensation based on simulation of temperature distribution in a vehicle cabin 30, p, 195-212. 
Li, W., Sun, J., 2013. Numerical simulation and analysis of transport air conditioning system integrated with passenger compartment. Appl. Therm. Eng. 50, 37-45. doi:10.1016/j.applthermaleng.2012.05.030

Marcos, D., Pino, F.J., Bordons, C., Guerra, J.J., 2014. The development and validation of a thermal model for the cabin of a vehicle. Appl. Therm. Eng. 66, 646-656. doi:10.1016/j.applthermaleng.2014.02.054

Mezrhab, A., Bouzidi, M., 2006. Computation of thermal comfort inside a passenger car compartment. Appl. Therm. Eng. 26, 1697-1704. doi:10.1016/j.applthermaleng.2005.11.008

Sanaye, S., Dehghandokht, M., Fartaj, A., 2012. Temperature control of a cabin in an automobile using thermal modeling and fuzzy controller. Appl. Energy 97, 860-868. doi:10.1016/j.apenergy.2012.02.078

Sevilgen, G., Kilic, M., 2012. Three dimensional numerical analysis of temperature distribution in an automobile cabin. Therm. Sci. 16, 321-326. doi:10.2298/TSCI1201321S

Swinbank, W.C., 1963. Long-wave radiation from clear skies. Q. J. R. Meteorol. Soc. 89, 339-348. doi:10.1002/qj.49708938105

Torregrosa-Jaime, B., Bjurling, F., Corberan, J.M., Di Sciullo, F., Paya, J., 2015. Transient thermal model of a vehicle's cabin validated under variable ambient conditions. Appl. Therm. Eng. 75, 45-53. doi:10.1016/j.applthermaleng.2014.05.074

Versteeg, H., Malalasekera, W., 2007. An introduction to computational fluid dynamics: The finite volume method, PEARSON Pr. ed.

Wischhusen, S., 2012. Modelling and Calibration of a Thermal Model for an Automotive Cabin using HumanComfort Library. Int. Model. Conf. 253-263. doi:10.3384/ecp12076253

Zhang, H., Dai, L., Xu, G., Li, Y., Chen, W., Tao, W.Q., 2009. Studies of air-flow and temperature fields inside a passenger compartment for improving thermal comfort and saving energy. Part II: Simulation results and discussion. Appl. Therm. Eng. 29, 2028-2036. doi:10.1016/j.applthermaleng.2008.10.005

Zhu, S., Demokritou, P., Spengler, J., 2010. Experimental and numerical investigation of micro-environmental conditions in public transportation buses. Build. Environ. 45, 2077-2088. doi:10.1016/j.buildenv.2010.03.004 